\title{
ANÁLISE CRÍTICA DO DISCURSO DE PRONUNCIAMENTOS DA POLÍCIA MILITAR DURANTE MANIFESTAÇÕES POPULARES
}

\author{
(Critical discourse analysis of military police \\ pronouncements during popular protests)
}

\author{
Micheline Mattedi Tomazi ${ }^{1}$ \\ (Universidade Federal do Espírito Santo - UFES) \\ Joelson Rocha ${ }^{2}$ \\ (Universidade Federal do Espírito Santo - UFES)
}

\begin{abstract}
The protests during the months of June and July 2013, in the state of Espirito Santo, demanded one Military Police justification of his performances on the streets. The aim of this paper is the analysis of the discursive strategies employed in these official pronouncements, mediated by the press capixaba, that purporting control the public discourse, in the pursuit of consensus building. For this, we make use of the theoretical and methodological parameters Critical Discourse Studies (ECD), by van Dijk (2003, 2010, 2012) as well as studies on the discourse of the media, by Charaudeau (2012). In the analysis, it was found as the discursive structures are built, to deny excess subtly coercive force, ensuring legitimacy to the actions of the corporation.
\end{abstract}

1. Doutorado em Estudos linguísticos pela Universidade Federal Fluminense. Professora Adjunta 2 do Departamento de Línguas e Letras na Universidade Federal do Espírito Santo (UFES), professora permanente no Programa de PósGraduação em Estudos Linguísticos (PPGEL/UFES), pesquisadora e líder do Grupo de Estudos sobre Discurso Midiático (GEDIM/UFES) e pesquisadora do Grupo de Estudos sobre a Articulação do Discurso (GEArtD/UFMG).

2. Mestrando do Programa de Pós-Graduação em Estudos Linguísticos (PPGEL/ UFES). Graduado em Comunicação Social e Letras pela Universidade Federal do Espírito Santo. Professor do Ensino Médio no Colégio Marista Nossa Senhora da Penha, Professor do Ensino Médio do Sistema Brasileiro de Educação. Pesquisador do Grupo de Estudos sobre Discurso Midiático (GEDIM/UFES). 
Keywords: Critical Discourse Studies, official discourse, strategies of denial.

\section{RESUMO}

Os protestos ocorridos durante os meses de junho e julho de 2013, no estado do Espírito Santo, exigiram da Polícia Militar justificativas da validade de suas atuações nas ruas. A proposta deste artigo consiste na análise das estratégias discursivas empregadas nesses pronunciamentos oficiais, mediados pela imprensa capixaba, que acreditamos propositar o controle do discurso público, na busca da formação de consenso. Para tanto, valemo-nos dos parâmetros teóricos e metodológicos dos Estudos Críticos do Discurso (ECD), de van Dijk (2003, 2010, 2012) e também dos estudos sobre o discurso das mídias, de Charaudeau (2012). Nas análises, verificou-se de que forma as estruturas discursivas são construídas para negar sutilmente o excesso de força coercitiva, garantindo legitimidade às ações da corporação.

Palavras-chave: Estudos Críticos do Discurso, discurso oficial, estratégias de negação.

\section{Introdução}

Os meses de junho e de julho de 2013 foram marcados em várias cidades brasileiras por manifestações populares, nas quais se reivindicaram ações diversas por parte dos governantes, entre elas, a redução da tarifa do transporte público, a não violência policial nas passeatas, o combate à corrupção e melhorias na educação. No Espírito Santo, uma mobilização chegou a reunir cerca de cem mil pessoas, em Vitória. Os confrontos entre policiais e manifestantes receberam ampla cobertura dos jornais locais, que concederam vozes às autoridades militares, no sentido de justificarem suas ações, consideradas por alguns setores violentas.

$\mathrm{O}$ presente estudo visa a analisar esses pronunciamentos institucionais mediados pela imprensa capixaba, com o objetivo de verificar as estratégias discursivas utilizadas pelos oficiais como forma de justificar a força empregada durante as manifestações e de legitimar o papel da polícia junto à população e ao Estado. Para tanto, foram 
selecionadas cinco publicações jornalísticas contendo falas oficiais de representantes da Polícia Militar, veiculadas pelo jornal A Gazeta, entre os dias 18 de junho e 17 de julho de 2013. A escolha dessas matérias jornalísticas, entre várias outras, justifica-se tanto pelo valor qualitativo do evento reportado quanto pelo teor desses discursos oficiais.

Esses pronunciamentos foram submetidos aos parâmetros teóricos, bem como aos procedimentos de análise propostos pelos Estudos Críticos do Discurso (ECD). Nesse campo de estudo, van Dijk (2003, 2010, 2012) analisou as estruturas e estratégias das construções discursivas no exercício ou legitimação do poder, incluindo aí as formas de negação do racismo. Acredita-se que também as falas das autoridades militares do Estado se valham dessas diversas estratégias para justificar ou até negar a violência empregada para conter os manifestantes. Os pronunciamentos selecionados foram publicados em domínio midiático, tendo como suporte o jornal impresso. A seleção que baliza o presente trabalho se articula também com os estudos dos discursos da mídia, realizados por Charaudeau (2012).

Para a análise, parte-se da hipótese de que os locutores desses discursos oficiais, ao ocuparem um privilegiado espaço na imprensa capixaba, selecionam determinadas formas linguísticas no sentido de um gerenciamento global da imagem da corporação. Dessa forma, constroem um discurso que legitima as estruturas de poder vigente, pois, tendo natureza de formação de consenso, o poder derivado desses pronunciamentos toma uma forma de hegemonia.

A partir desses parâmetros, foi possível gerar alguns questionamentos, tais como: Que estruturas sutis de sentido compõem as justificativas das ações policiais? Que propriedades discursivas revelam a negação da força abusiva empregada pela polícia contra os manifestantes? Como a construção desses discursos veiculados pela mídia capixaba os faz adquirir status de verdade? De que forma esses pronunciamentos contribuem na criação de um consenso, fundamental à hegemonia?

Com vistas a aproximar respostas às questões acima destacadas, o artigo encontra-se dividido em quatro seções. Na primeira, 
abordamos os Estudos Críticos do Discurso (ECD) como instrumento para análise da reprodução discursiva do poder. $\mathrm{Na}$ sequência, especificamos os discursos oficiais no espaço midiático, sua busca pela construção de efeito de verdade e sua prática como exercício de poder. Depois, apresentamos os procedimentos de análise, a que foram submetidos os pronunciamentos oficiais. Por fim, realizamos as análises dessas falas, buscando de que forma elas exercem e legitimam um poder hegemônico.

\section{Os instrumentos de análise da reprodução discursiva de abuso de poder}

Os Estudos Críticos do Discurso constituem um conjunto de práticas acadêmicas com a finalidade de revelar como operam, no discurso, os exercícios de poder, especificamente as práticas de abuso e de ilegitimidade. As pesquisas nesse campo de estudo buscam examinar como as estruturas discursivas podem variar ou serem influenciadas pelas composições sociais. Propriedades sonoras e visuais, estruturação dos elementos constituintes das frases, seleção lexical, semântica das pressuposições, encaminhamento argumentativo e estratégias de polidez, por exemplo, são variações que podem revelar tentativa de confirmação e reprodução de abuso de poder. Esse campo de estudos se mostra, portanto, como uma ponte entre as análises que focalizam os macroníveis das estruturas sociais e as que priorizam os microníveis, referentes às práticas cotidianas de linguagem.

Para van Dijk (2010, p. 177), embora o exercício do poder seja fundamental para o funcionamento das sociedades, há práticas abusivas do poder que se revelam nas estruturas discursivas de grupos ou instituições. O poder é entendido nessa abordagem em termos de controle de atos e mentes dos grupos dominados e pode ser distinto, de acordo com os recursos empregados para exercê-lo: poder coercitivo, poder econômico, poder baseado no conhecimento. Para o autor, o discurso produzido pelos agentes poderosos se torna ilegítimo 
quando se enquadra em termos de consequências mentais negativas dessa dominação, produzindo ou perpetuando violações aos direitos humanos ou civis ou promovendo desigualdade social e favorecimento dos que dominam.

Esses grupos de poder agem também pelo controle do discurso e, por consequência, pelo controle das mentes. O acesso ao conhecimento e à informação é notadamente constituído pela definição de quem tem acesso à produção dos discursos. A maioria das pessoas possui apenas afluência às conversas familiares ou a espaços controlados de participação, como um aluno em uma aula ou uma testemunha de um acidente em uma notícia. Se discursos públicos são produzidos por agentes específicos, que controlam o conteúdo e o gênero dos discursos, a repetição deles pode criar base consensual propícia à formação de "hegemonia", conforme conceituado por Gramsci (GRAMSCI, 1971, apud van DIJK, 2010, p. 118).

Estudar os sistemas de estruturas da fala e da escrita da Polícia Militar torna-se, nesse sentido, produtivo, pois pode funcionar como ponte entre o micronível das construções linguísticas e a hegemonia do Estado, por meio da sua força armada. É, pois, este o tópico que será tratado na próxima seção.

\section{Discurso oficial nos meios jornalísticos: exercício de controle dos discursos públicos}

O controle do discurso público encontra nos pronunciamentos oficiais vasta possibilidade de efetivação. Como sugere van Dijk (2010, p. 73), "por meio do uso seletivo de fontes de informação, rotinas jornalísticas consagradas e seleção de assuntos para as histórias, a mídia jornalística decide quais atores serão representados na arena pública, o que será dito a respeito dele e, em especial, como será dito”.

Dessa forma, diante de acontecimentos que envolvam as corporações, organizações ou órgãos públicos, a fala institucional 
exerce forte peso na formação da opinião pública, visto a notoriedade que ela adquire em comparação aos depoimentos de pessoas comuns envolvidas no mesmo episódio. Para van Dijk (2010, p. 81), "esse viés tendencioso surge através do tempo e tipo de entrevistas". Enquanto fontes comuns são entrevistadas no próprio local do fato relatado, sob forte pressão emocional, as fontes oficiais são ouvidas em seus escritórios ou gabinetes, locais silenciosos. Esse aspecto das condições de produção determina, em boa medida, parte do conteúdo veiculado, já que às falas institucionais é oferecido tempo de elaboração, enquanto as falas populares são produzidas sob o efeito do acontecimento. Assim, os discursos oficiais são produto de elaboração e de monitoramento, visando ao gerenciamento global da imagem.

O acesso a específicas formas de discurso também contribui para a promoção de legitimidade aos discursos oficiais. Constantemente as declarações ou justificativas tornam-se públicas sob a forma de notas oficiais, gênero a cuja produção a maioria das pessoas não tem acesso. Outros exemplos dessas formas privilegiadas de discurso são as entrevistas coletivas à imprensa e o press release.

Com isso, a mídia vai cristalizando consensualmente em verdade aquilo que é dito por quem tem acesso ao discurso, ou seja, por quem detém o poder hegemônico. Tal tendência ao consenso do discurso oficial sobre a opinião pública pode ocorrer porque essas condições de produção privilegiadas promovem, sobre o que é dito oficialmente, um efeito de verdade. Esse conceito foi explicitado por Charaudeau (2012). Para o autor, trata-se daquilo que o sujeito, a partir de sua subjetividade em relação com o mundo, acredita ser verdadeiro, aderindo a essa ideia. Mas esse processo não se efetiva exclusivamente por escolhas próprias, mas, sim, ocorre nos processos interativos da linguagem, uma vez que "o efeito de verdade não existe, pois, fora de um dispositivo enunciativo de influência psicossocial, no qual cada um dos parceiros da troca verbal tenta fazer com que o outro dê sua adesão a seu universo de pensamento e de verdade”, conforme palavras de Charaudeau (2012, p. 49). 
Esse controle sobre quem produz os discursos públicos condena os sujeitos comuns a terem vozes apenas nas conversas cotidianas. Em caminho oposto, os discursos oficiais vão adquirindo efeito de verdade e se tornando consenso entre a opinião pública. Parece ficar evidente, nesse processo todo, o consequente controle das mentes.

\section{Estratégias e estruturas discursivas na produção de discursos tendenciosos}

O exercício e a manutenção do poder e de suas bases ideológicas se consistem pela formação de consenso e de aceitação. Como as ações comunicativas são um componente importante na produção de tal estado, torna-se crucial analisar de que forma os discursos reproduzem e perpetuam o poder social. No caso específico desta pesquisa, acredita-se ser fundamental o estudo das estruturas discursivas das falas oficiais da Polícia Militar para revelar a busca de consenso e de aceitação desses discursos e, por consequência, da validade de suas ações.

Os mecanismos para tal análise estão, de acordo com van Dijk (2010), nos sistemas e estruturas variáveis da fala ou da escrita, adaptáveis aos interesses do locutor. Por exemplo, embora existam certas estruturas sintáticas obrigatórias, por força de propriedades gramaticais da língua, há outros elementos e estruturas que podem variar, de acordo com a situação social do discurso. São essas possibilidades de adaptação e de escolhas que permitem descrições qualitativas dos detalhes das estruturas discursivas:

(...) os Estudos Críticos do Discurso (ECD) se concentrarão, em geral, naqueles sistemas e estruturas da fala ou da escrita que podem variar em função de condições sociais relevantes do uso linguístico, ou que podem contribuir para consequências sociais específicas do discurso, tais como influenciar crenças e ações sociais dos ouvintes e leitores.

(van DIJK, 2010, p. 14) 
Tais variações podem ser perceptíveis em vários níveis, incluindo elementos semióticos. Nessa perspectiva, enumera van Dijk (2010: 136-137) uma lista dessas estruturas variáveis, que possibilitam verificar intenções discursivas de preservação de poder. A sequência se inicia pelos elementos não verbais, como, por exemplo, o layout da página, as imagens escolhidas ou as angulações das fotos. Por meio desses elementos, pode ser possível constatar ênfases negativas sobre "Eles".

Também a sintaxe, na maneira como se sequenciam os termos de uma frase, pode ser um indicador de discurso tendencioso. É possível enfatizar ou atenuar ações manipulando os termos que ocupam as posições mais importantes e de maior visibilidade da frase. Van Dijk (2010: 136) afirma que estudos verificaram ocupações de posições mais topicalizadas quando se trata da ação negativa das minorias, mas, quando as autoridades estão ligadas a atos negativos, aparecem em posições posteriores ou são deixados de fora da sentença. A exploração das estruturas da voz passiva é um dos exemplos desse tipo de mecanismo.

Outro recurso de representação negativa do outro está nas escolhas lexicais. Para van Dijk (2012: 238), esse tipo de variação é "particularmente sensível ao contexto":

Por meio das palavras que usam, os falantes mostram suas identidades sociais, suas relações enquanto participantes, sua adaptação à audiência, seu estado de espírito, suas emoções, seus valores, suas opiniões e atitudes, seus propósitos, seu conhecimento e os tipos de situações (in)formais ou institucionais em que estão falando ou escrevendo. Em suma, poucas categorias contextuais não são de modo algum marcadas pela escolha do léxico.

(van DIJK, 2012, p. 238)

Entre as categorias contextuais a serem consideradas, destacamos a identidade social e estereótipos, usos especializados versus não especializados e a posição social. Por mais que os discursos oficiais, objeto deste artigo, apresentem-se como uma ação discursiva controlada, pode ser possível perceber, por meio dos termos 
atribuídos a alguns setores sociais, valorização ou desqualificação de manifestantes, às vezes recorrendo a rótulos negativos. Além disso, nos discursos oficiais, é previsível a presença de termos técnicos, de acordo com área de atuação desse agente do discurso. Também parece claro que a posição social desses locutores do discurso oficial, hierarquicamente superiores, determina considerável parte dessas escolhas lexicais.

Há ainda estratégias semânticas que podem ser desenvolvidas na fabricação de imagem de si ou do outro. Van Dijk (2010: 137) cita o significado local e o significado global do discurso. Segundo o estudioso, na oração, o significado pode ser vago ou indireto referente a algumas ações e detalhado e preciso sobre outras. Num aspecto mais amplo, é possível "selecionar ou enfatizar tópicos positivos para Nós (tais como ajuda e tolerância), e negativos para Eles (tais como crime, desvio comportamental ou violência)". Às vezes, esse sistema de significados cria e apresenta contrastes que conferem destaque às diferenças. Os dispositivos retóricos podem também revelar discurso tendencioso. O uso de metáforas, de metonímias, de hipérboles, de eufemismos pode centralizar a atenção na informação positiva ou negativa sobre si ou sobre o outro.

Ao se referir aos discursos produzidos sobre as minorias, van Dijk (2010, p. 62) identifica, ainda, a presença de estratégias globais que podem revelar depreciação ou valorização. Trata-se da "autoapresentação" positiva e da "outro-apresentação" negativa. Segundo seus estudos e enfoque, os discursos sobre as minorias podem manifestar experiências e opiniões negativas sobre alguns grupos, por meio de estratégias semânticas e retóricas, como argumentações ou narrativas concretas. Junto a isso, procede-se a um sistematizado contrabalanceamento, por meio da fabricação de imagem de tolerante, não racista, compreensivo, por exemplo.

Um processo discursivo de "auto-apresentação" positiva e "outro-apresentação" negativa particularmente importante a esta pesquisa está nas estratégias sutis de negação. Para van Dijk (2010, p. 157 -158), especificamente quanto ao discurso racista nas conversações diárias, as falas cotidianas tendem a incluir ressalvas e 
outras formas de negação. Trata-se de "movimentos semânticos com uma parte positiva sobre Nós e uma parte negativa sobre Eles” (op. cit, 2010, p. 142). Alguns exemplos dessas estratégias encontram-se reportados no Quadro 1 abaixo:

Quadro 1 - Exemplos de ressalvas

- Negação aparente: Nós não temos nada contra negros, mas...

- Concessão aparente: Alguns deles são inteligentes, mas em geral...

- Empatia aparente: É claro que refugiados tiveram problemas, mas...

- Ignorância aparente: Eu não sei, mas...

- Desculpa aparente: Desculpe-me, mas...

- Inversão (culpar a vítima): Não eles, mas nós é que somos as reais vítimas...

- Transferência: Eu não me importo, mas meus clientes...

Fonte: van Dijk (2010, p.142)

Os dispositivos categoriais, dispostos acima, foram tratados pelo autor como "aparentes" porque a primeira parte pode ser considerada uma forma de manejo das impressões, enquanto o resto da sentença reforçará características negativas dos Outros, contradizendo assim a primeira parte "positiva" (van Dijk, 2010, p. 143). Segundo o autor, as negações consistem, especificamente, em uma estratégia de "autoapresentação" positiva do grupo. Elas fazem parte do propósito de defesa e frequentemente recorrem a acusações implícitas ou explícitas. Nessa estratégia, a condição maior da responsabilidade pelo ato negativo reside nas boas intenções: o propósito positivo justifica a ação negativa. A eficácia disso está no fato de não haver como provar a negatividade das intenções. Dessa forma, constrói-se, portanto, a justificativa: há uma consequência negativa, mas as intenções foram boas. 
Em seus estudos, van Dijk também classifica os tipos de negação, que seguem de maneira detalhada no Quadro 2 abaixo:

Quadro 2 - Tipos de negação

- Negação do ato ("Eu não fiz / não disse isso de jeito nenhum")

- Negação do controle ("Eu não fiz / não disse aquilo de propósito")

- Negação da intenção ("Eu não quis dizer isso"; "Você entendeu errado")

- Negação do propósito ("Eu não fiz / não disse isso para...”)

Fonte: van Dijk (2010, p.162)

Além da negação, existem outras estratégias cognitivas e sociais que, de uma forma ou de outra, estão relacionadas às negações. A justificativa é um recurso recorrente nas negações. Às vezes, pode aparecer em forma de desculpa, mas também pode caracterizar o ato negativo como sendo de legítima defesa ou produzido por culpa do outro. Nesse recurso, o ato em si não é negado, mas nega-se a responsabilidade, já que o outro é o culpado. Essa transferência da culpa caracteriza a escusa, que, em um grau mais acentuado, pode chegar à provocação e culpa da vítima.

A mitigação também constitui uma forma sutil de negação, pois consiste em amenizações, às vezes por meio de eufemismo, de atos negativos. Ainda existe a reversão. Por meio dessa estratégia, o outro é que é visto como intolerante, violento, antidemocrático. A reversão é, portanto, uma estratégia de contra-ataque.

A partir desses conceitos, pretendemos analisar as propriedades discursivas utilizadas nas falas oficiais da Polícia Militar, a fim de descrever os processos por meio dos quais se construíram as justificativas para o uso de força coerciva nas ações dessa corporação durante as manifestações ocorridas em junho e julho de 2013. 


\section{Análise discursiva crítica dos discursos oficiais}

Os pronunciamentos oficiais submetidos aos dispositivos de análise dos ECD nesta pesquisa foram recolhidos de reportagens veiculadas pelo jornal "A Gazeta", do Espírito Santo, ou de entrevistas concedidas por oficiais da Polícia Militar a esse mesmo meio jornalístico. Esses textos, reproduzidos nos anexos deste artigo, foram publicados nos dias 18 e 28 de junho e 05, 06 e 17 de julho. Todos repercutiram graves enfrentamentos entre polícia e manifestantes, ocorridos nos dias anteriores à publicação.

Como a fonte de todos os pronunciamentos oficiais analisados está em reportagens e entrevistas, gêneros jornalísticos, é preciso, de antemão, reforçar o que defende Charaudeau (2012, p. 19-20) com relação à mídia como criadora de informação: "as mídias não transmitem o que ocorre na realidade social, elas impõem o que constroem do espaço público". Elas, portanto, mostram apenas "um fragmento amplificado, simplificado, estereotipado do mundo". Por isso, é necessário legar à empresa jornalística a seleção do que foi publicado. Para que essa influência não seja ampliada, adotou-se nesta pesquisa a seleção apenas de falas diretas, excluindo as paráfrases construídas pelos jornalistas-narradores nos discursos indiretos.

Preliminarmente, a observação das condições de produção revela muito sobre o efeito de verdade produzido por esses discursos oficiais. Pode-se dizer que, nas cinco participações analisadas, as falas foram produzidas em condições privilegiadas. Em nenhuma das matérias jornalísticas, a justificativa ou comentário oficial surgiram de um participante direto do acontecimento. A voz que fala pela corporação se manifesta ora pelo secretário estadual de Segurança, André Garcia, ora pelo comandante-geral da Polícia Militar, coronel Edmilson Santos, sempre de seus locais de trabalho; portanto, longe da tensão e tumulto das manifestações. Em contraposição a isso, os manifestantes foram sempre entrevistados nas ruas, sendo que os acusados de vandalismo ou de radicalidade, especificamente, não apresentaram falas em nenhum dos textos estudados. 
Outro privilégio observado está no gênero do discurso a que a corporação tem acesso, diferentemente dos manifestantes comuns. $\mathrm{Na}$ edição de 28 de junho, as declarações oficiais vieram sob a forma de entrevistas do secretário estadual de Segurança e do comandantegeral da Polícia Militar. Em quatro das reportagens aqui analisadas, a visão dessa corporação aparece em uma seção constituinte da reportagem, mas destacada, o que pode atrair a essa fala uma atenção e um valor maior dos leitores. Quando as fontes são manifestantes, as falas aparecem em meio ao texto principal, ao longo da narração jornalística, desfavorecendo essas versões, tidas como não oficiais.

Especificamente, quanto ao texto escrito, o léxico explorado por esses representantes da segurança pública sugere uma tentativa de validar as ações da polícia e de desqualificar os manifestantes. Nas referências aos ativistas, percebe-se uma gradação negativa no transcorrer do tempo. Se, no início, Garcia utilizou a expressão grupo radical (A Gazeta, 18/06/2013 p. 4), dez dias depois, a referência feita pelo secretário a esse mesmo grupo se realizou por bandidos infiltrados, baderneiros enfrentando o Estado, vândalos, pessoas armadas e pessoas perigosas (A Gazeta, 28/06/2013 p. 10). Também o comandante-geral da Polícia Militar, na mesma edição, utilizou-se dos termos vândalos e criminosos. Essas referências são acompanhadas de outros elementos lexicais, que compõem uma representação negativa e estereotipada dos manifestantes, em expressões tais como: prática de crimes, enfrentamento, assaltos, depredações e saques, que acompanham tais descrições (A Gazeta, 28/06/2013, p. 10).

Observa-se, por meio da comparação desses termos e expressões, um percurso semântico de exclusão, desses alvos da repressão policial, do grupo geral de manifestantes. Isso pode ser interpretado como uma estratégia, por meios discursivos, de legitimidade das ações policiais. Van Dijk, nos seus estudos sobre a negação do racismo, analisa essa estratégia de "fazer bloquear inferências dessa instância específica para uma imagem mais geral" (van Dijk, 2010, p.158). Ao distanciar os revoltosos dos manifestantes comuns, cria-se uma categoria exclusiva sobre a qual a legitimidade da ação violenta da polícia pode ser mais facilmente absorvida pela opinião pública. Em outro trecho, Garcia torna mais explícita esta 
intenção discursiva e cognitiva: "O que aconteceu na praça da Terceira Ponte foi uma ação de radicais, mas a manifestação, em sua maior parte, transcorreu sem problemas" (A Gazeta, 05/07/2013, p. 5).

As palavras ou expressões referentes à corporação estão sempre relacionadas à função oficial desses agentes da segurança, o que reforça ora profissionalismo, ora o caráter institucional da corporação. Eles são tratados por policiais, a polícia, o policiamento, a PM, a tropa, Estado, efetivo, segurança pública, policiamento velado, flancos de atuação (A Gazeta, 28/06/2013, p. 10). A seleção de variantes técnicas também fortalece a imagem profissional da corporação, como se pode notar nesta frase do secretário: "A polícia militar agiu dentro da técnica de controle de distúrbio civil” (A Gazeta, 05/07/2013, p. 5). A comparação entre os tratamentos deixa clara a polarização: de um lado, manifestantes radicais, violentos, criminosos; de outro, profissionais, estrategistas, organizados, oficiais.

Nas descrições das ações, também há a exploração de itens lexicais que amenizam ou reforçam aquilo que é negativo. A violência policial foi justificada pela fala do secretário de Segurança: "Nossa intenção não era interferir na liberdade de protesto...”, sem especificar como os policiais agiram (A Gazeta, 18/06/2013, p. 4). Em seguida, ele descreveu as ações dos manifestantes: “(...) um grupo radical, que jogou pedras, garrafas e latas de cerveja contra a tropa”. $\mathrm{Na}$ mesma reportagem, o secretário justifica que "foi preciso dispersar o grupo", seguido de "Eles lançaram pedras, garrafas e latas de cerveja sobre a tropa...”. Os verbos interferir e dispersar são, certamente, mais eufemísticos do que jogar e lançar, que demonstram ação violenta.

Os elementos linguísticos que preenchem as posições sintáticas das frases proferidas pelos representantes da polícia também revelam um discurso polarizado. Sempre que as ações dos manifestantes são negativas, os agentes são colocados em posições de destaque, como sujeito da sentença. Em contrapartida, nas descrições das ações previsivelmente mais condenadas pela opinião pública, o agente da ação é escondido em posições menos visíveis ou é excluído da sentença. Com a finalidade de se comparar essas elaborações sintáticas, seguem alguns exemplos no Quadro 3: 


\section{Quadro 3 - Posição sintática dos agentes em ações positivas e negativas em sentenças das reportagens analisadas}

\begin{tabular}{|c|c|c|}
\hline \multicolumn{3}{|c|}{ Posição sintática dos agentes em ações positivas e negativas. } \\
\hline Ações & Sentença & Agente \\
\hline \multirow{3}{*}{$\begin{array}{l}\text { Negativas dos } \\
\text { policiais }\end{array}$} & $\begin{array}{l}\text { "Foi preciso dispersar o grupo para que a } \\
\text { situação não fugisse ao controle..." (A Gazeta, } \\
\text { 18/06/2013: 4). }\end{array}$ & - \\
\hline & $\begin{array}{l}\text { "Infelizmente, chegou a esse ponto" (A } \\
\text { Gazeta, 18/06/2013: 4). }\end{array}$ & - \\
\hline & $\begin{array}{l}\text { "Para evitar que isso acontecesse, impedimos } \\
\text { que a população subisse a pé de Vila Velha } \\
\text { para Vitória" (A Gazeta, 28/06/2013: 10). }\end{array}$ & Sujeito oculto \\
\hline \multirow{3}{*}{$\begin{array}{l}\text { Negativas dos } \\
\text { manifestantes }\end{array}$} & $\begin{array}{l}\text { “... um grupo radical, que jogou pedras, } \\
\text { garrafas e latas de cerveja contra a tropa da } \\
\text { Polícia Militar, ferindo um soldado a pedrada” } \\
\text { (A Gazeta, 18/06/2013: 4). }\end{array}$ & Sujeito claro \\
\hline & $\begin{array}{l}\text { "E essas pessoas perigosas (...) estão do seu } \\
\text { lado, do lado de um pai, de uma mãe de família, } \\
\text { de uma criança" (A Gazeta, 28/06/2013:10). }\end{array}$ & Sujeito claro \\
\hline & $\begin{array}{l}\text { "Um dos rapazes presos ontem estava com uma } \\
\text { pistola 380..." (A Gazeta, 28/06/2013: 10). }\end{array}$ & Sujeito claro \\
\hline \multirow{3}{*}{$\begin{array}{l}\text { Positiva dos } \\
\text { policiais }\end{array}$} & $\begin{array}{l}\text { "A polícia está preparada para evitar que isso } \\
\text { aconteça" (A Gazeta, 28/06/2013: 10). }\end{array}$ & Sujeito claro \\
\hline & $\begin{array}{l}\text { "(...) a polícia recebeu a informação de que } \\
\text { havia um número grande de vândalos entre } \\
\text { manifestantes" (A Gazeta, 28/06/2013: 10). }\end{array}$ & Sujeito claro \\
\hline & $\begin{array}{l}\text { "A PM sempre age com a intenção de preservar } \\
\text { a segurança e a integridade física das pessoas } \\
\text { de bem que estão protestando" (A Gazeta, } \\
\text { 28/06/2013: 10). }\end{array}$ & Sujeito claro \\
\hline
\end{tabular}

O Quadro 3 permite destacar que, na estrutura da sentença, a posição dos agentes de ações negativas e positivas, combinada com as propriedades semânticas dos itens lexicais mobilizados pelo locutor, cria representações positivas à corporação do Estado e negativa aos ativistas. Na primeira linha do quadro, por exemplo, o agente da ação 
negativa foi escondido pela busca de uma estrutura que priorizasse um termo vago, sem detalhamentos, situação. No segundo exemplo, acima, chegou a esse ponto não deixa claro nem as ações produzidas, nem o agente desses acontecimentos. Aliás, situação e ponto não são, a princípio, palavras semanticamente negativas.

Essa busca por termos vagos ou indiretos para as ações policiais e de termos mais detalhados para as ações dos manifestantes cria um significado local favorável à corporação. As investidas dos manifestantes são descritas com mais precisão que as da força estatal. Veem-se, aliás, mais palavras referentes às armas dos manifestantes: latas de cerveja, pedras, pistola, carabina 44 (A Gazeta, 18/06/2013, p. 4; A Gazeta, 28/06/2013, p. 10) que de termos que revelam o armamento policial. Dessa forma, cria-se globalmente uma representação dos manifestantes como violentos, radicais, fora de controle, ameaçadores, enquanto a PM é relacionada à ordem, estratégia e preparo.

Esse detalhamento das ações negativas dos manifestantes também é construído por meio do que van Dijk (2010:137) sugere como esquemas. As descrições e narrações das ações policiais finalizam, às vezes, com uma conclusão que reforça a legitimidade e eficácia da corporação. Por exemplo, "Não atuamos apenas com suposições, mas com informações de quem está em campo" (A Gazeta, 28/06/2013, p. 10) é estrategicamente estruturado após a narração do episódio de enfrentamento entre policiais e manifestantes em cima da ponte que liga Vitória a Vila Velha. Em outro exemplo, toda a descrição das características dos revoltosos é finalizada com uma tentativa de persuasão no sentido de esvaziar a mobilização: "A gente pede que os cidadãos de bem pensem duas vezes antes de ir ao protesto..." (A Gazeta, 28/06/2013, p.10).

Todos esses exemplos comprovam a criação, pelas autoridades de segurança, de um discurso polarizado, impregnado de estratégias de "auto-apresentação" positiva e de "outro-apresentação" negativa. Com essas artimanhas discursivas, procede-se a um gerenciamento global da imagem, transmitindo uma representação positiva da corporação e produzindo consenso entre a opinião pública.

O próprio objetivo maior desses pronunciamentos, a justificativa das operações policiais, também obedece a essa intenção discursiva 
e cognitiva. Na busca de legitimação às ações, nega-se a violência das intervenções policiais por meio de ressalvas. Isso fica claro em várias passagens, em que a responsabilidade da polícia é atenuada pela existência de uma boa intenção. O secretário de segurança, André Garcia, declarou: "Nossa intenção não era interferir na liberdade de protesto, mas tivemos que dispersar um grupo radical..." (A Gazeta, 18/06/2013, p. 4). Observa-se nessa fala a negação de uma intenção de caráter prejudicial; logo, infere-se que a corporação não tem culpa da violência empregada pelos agentes policiais. Essa fala apela também para a estratégia da escusa e da reversão, porque aponta o outro como culpado, já que, de acordo com o secretário, foi a radicalidade do outro que provocou a ação policial. Essa reversão pode produzir efeito de naturalização das atuações violentas da polícia, como no exemplo desta declaração, de Garcia: "Infelizmente, o enfrentamento de manifestantes era esperado, porque esse tipo de comportamento foi registrado em todos os protestos." (A Gazeta, 05/07/2013, p.5).

Outra fala em que se verifica a estratégia da reversão está no pronunciamento do Coronel Edmilson dos Santos: "Desde a ditadura, a PM mudou muito, mas não mudou a ação de vândalos que utilizam a luta democrática para destruir e causar tumulto" (A Gazeta, 17/06/2013, p. 8). Aqui, é clara a transferência de culpa e a inversão dos papéis. De acordo com o que foi dito pelo oficial, a polícia, entidade historicamente relacionada a repressões, é democrática; os manifestantes, no entanto, são antidemocráticos.

Em mais uma fala do secretário de segurança, a boa intenção da polícia é utilizada como parte positiva da sentença, justificando a ação negativa que sequencia a primeira: "Para evitar que isso ocorresse, impedimos que a população subisse a pé de Vila Velha para Vitória" (A Gazeta, 28/06/2013, p.10). Em outra passagem, o mesmo locutor expressa: "Infelizmente, chegou a esse ponto" (A Gazeta, 18/06/2013, p. 4). Trata-se, desta vez, de um caso de mitigação, já que a força empregada é eufemizada, minimizada.

Tais estratégias discursivas expostas aqui comprovam a criação de um discurso que nega a força excessiva da polícia, ao mesmo tempo em que transfere a culpa para o outro grupo. Dessa forma, produz-se 
um efeito de verdade, que pode ser aceito plenamente ou parcialmente pela opinião pública.

Em alguns pronunciamentos, inclusive, percebe-se a admissão de que tal corporação detém a verdade, acima de outros setores da sociedade. No episódio da apreensão das câmeras pelos policiais, Garcia afirmou: "Nós vimos parte da filmagem, não vimos toda. Então, ali, nós vamos verificar, por um procedimento administrativo disciplinar, a verdade dos fatos" (A Gazeta, 06/07/2013, p. 9). Como se pode observar, não bastaram as condenações da Universidade Federal do Espírito Santo ou da Ordem dos Advogados à violência empregada pelos agentes policiais. A inferência que se pode fazer nessa declaração é a de que a má conduta somente poderá ser comprovada pela própria corporação, que é, portanto, exclusiva detentora da verdade.

\section{Considerações finais}

A análise dos pronunciamentos oficiais dos representantes da polícia, quando submetidos aos parâmetros teóricos e procedimentos de abordagens dos Estudos Críticos do Discurso, revelou estratégias discursivas que promovem a legitimidade das operações policiais durante as manifestações nas cidades de Vitória e de Vila Velha, em junho e julho de 2013. Por meio de uma escolha lexical tendenciosa, detalhamentos ou imprecisões de ações negativas, manipulação sintática dos termos das sentenças, entre outros recursos linguísticos, representaram-se negativamente os manifestantes e positivamente a corporação do Estado.

Como as reportagens e entrevista concederam às vozes dos oficiais um espaço privilegiado, tal escopo de poder valeu-se desse terreno favorável à criação de uma "auto-apresentação" positiva e de uma "outro-apresentação" negativa, importantes no gerenciamento global da imagem. Além disso, justificou-se a repressão policial, por meio da negação de que houve excesso de força coercitiva, recorreu-se a mitigações, escusas e reversão de culpa.

Esse tipo de discurso pode, se não houver um olhar atento de seu ouvinte ou leitor, produzir efeito de verdade, constituindo consenso 
entre a opinião pública e perpetuando o abuso de poder, tanto coercitivo, quanto discursivo. É na proposição de uma leitura mais crítica e atenta dos pronunciamentos oficiais que reside a contribuição deste artigo. Trata-se, enfim, da possibilidade de investirmos em uma educação discursiva que nos permita atenuar o controle das mentes e, em condições propícias, agir contra as forças abusivas de poder.

Enviado em: julho de 2013 Aprovado em: setembro de 2013 michelinetomazi@gmail.com joerocha@hotmail.com.br

\section{Referências bibliográficas}

CHARAUDEAU, P. Discurso das mídias. Tradução de Ana M. S. Corrêa. 2. ed., 1 ${ }^{\text {a }}$. reimpressão. São Paulo: Contexto, 2012.

FELIZ, C. Governo: PM agiu certo. In: Jornal A Gazeta: Cidades. 5 de julho de 2013, p. 5.

. "Ação da PM é quase perfeita", diz coronel. In: Jornal A Gazeta: Cidades. 17 de julho de 2013, p. 8.

FERNANDES, V. "Protesto tinha mil bandidos armados". In: Jornal A Gazeta: Cidades. 28 de junho de 2013, p. 10.

GRAMSCI, A. Prison notebooks. New York: International Publishers, 1971.

NETO, A. Uma lata, e começa confronto com a PM. In: Jornal A Gazeta: Cidades. 18 de junho de 2013, p. 4.

SOARES, L. PM apreende câmeras de estudantes da Ufes. In: Jornal A Gazeta: Cidades. 6 de julho de 2013, p. 9.

VAN DIJK, T. A. Ideologia y discurso: uma introducción multidisciplinaria. Madri: Ariel Linguística, 2003. . Discurso e poder. São Paulo: Contexto, 2010.

. Discurso e contexto: uma abordagem sociocognitiva. Tradução de Rodolfo Ilari. São Paulo: Contexto, 2012. 
CIDADES 5 SEXTA.FELAR,

O POVO NAS RUAS

\section{GOVERNO: PM AGIU CERTO}

Secretário explica que proposta era liberar o tráfego na ponte
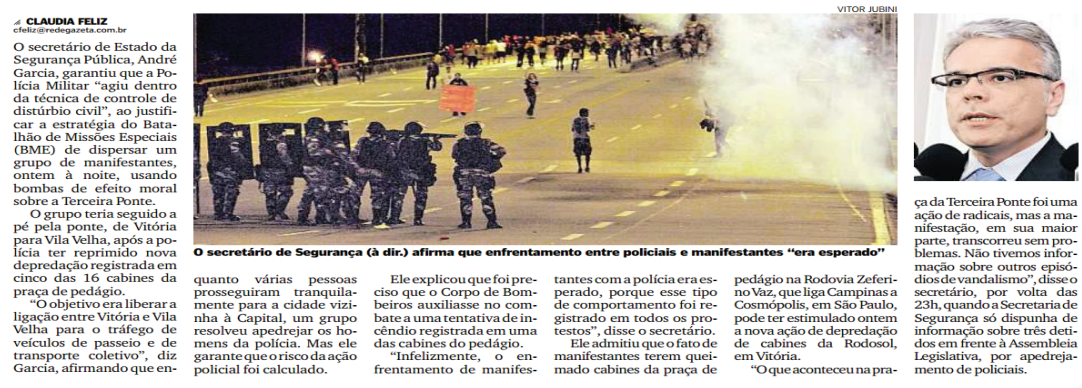
quanto várias pessoas prosseguiram tranquila-
mente para a cidade vizi-

Ele explicouque foipretantes coma polícia era es- pedágio na Rodovia Zeferi-
perado, porque esse tipo noVaz, queliga Campinasa beiros auxiliasse no com- de comportamento foi re- Cosmópolis, em São Paulo, nha à Capital, um grupo mens da polícia. Mas ele bate a uma tentativa dein-
cêndio registrada em uma garante queoriscodaac
policial foi calculado.

"Infelizmente, en- manifestantes tereme fatode

a nova ação de depredação de cabines da Rodosol,

ça da Terceira Fonte foi uma açăo de radicais, mas a manifestaçāo, em sua maior parte, transcorreu sem promaç̃o diosdevandalismo", disseo secretario, por volta das 23h, quando a secretariade Segurança só dispunha de dos em frente à Assembleia Legislativa, por apedreja-

Anexo 1 - Reportagem (A GAZETA, 05/07/2013, p. 5) 


\section{UMA LATA, E COMEÇA CONFRONTO COM A PM}

\section{Protesto seguia pacífico, mas virou guerra no fim da noite}

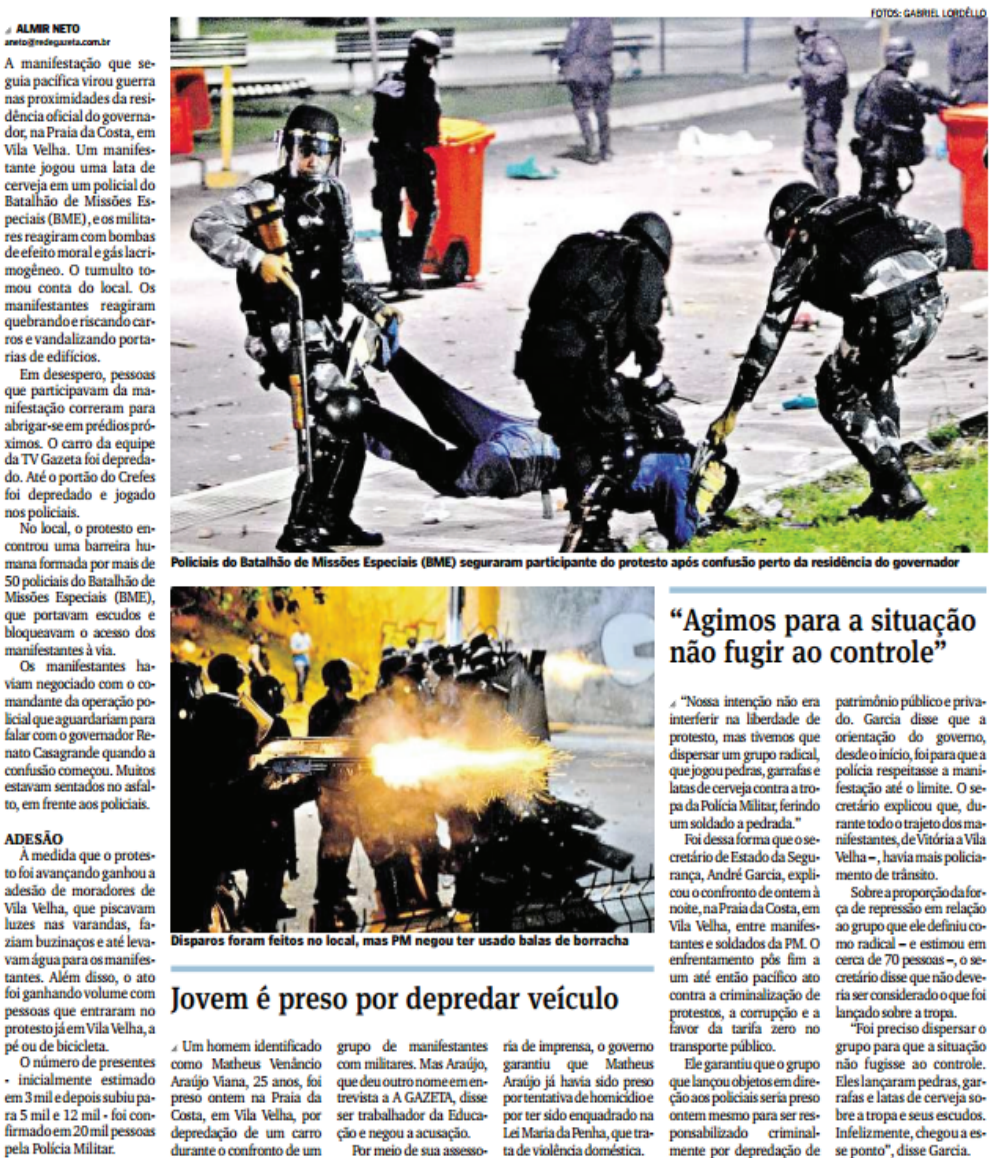

Anexo 2 - Reportagem (A GAZETA, 18/06/2013: 4). 


\section{"PROTESTO TINHA MIL}

\section{Para secretário de Segurança, solução não é questão de efetivo}

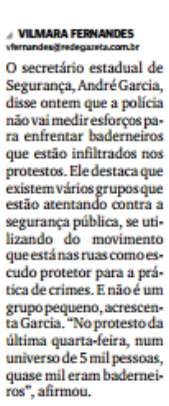

Que avaliaçăo o senhor fazdos protestos?

O que observamos nas últimas duas ediçōes é a presença forte de grupos infiltrados. E não é um grupopequeno. Num universode 5 mil pessoas, como a manifestação de on. tem (quarta-feira), quase mil eram bademeiros en qrentando o Estado, porque ao enfrentar a polícia
vocé enfrenta o Estado. vocé enfrenta o Estado. tos, depredaçoues, pratica. ram o que o movimento não pregou na marcha dos 100 mil (noúltimodia

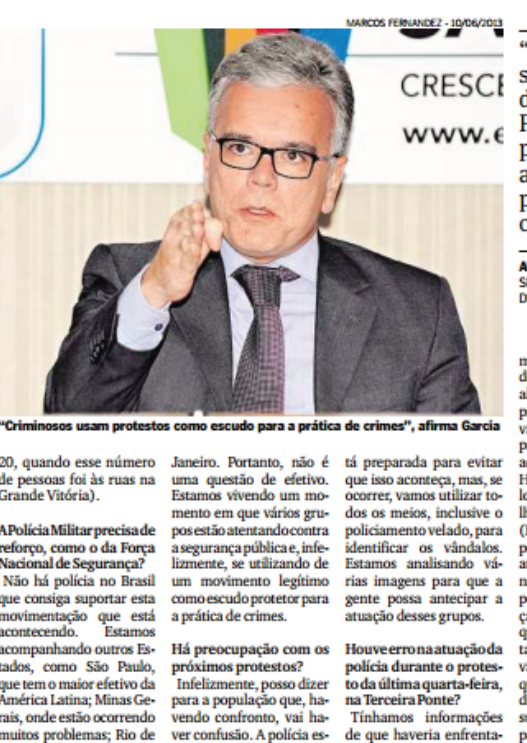

"Muitos estão se aproveitando do movimento.

Prendemos

pessoas

armadas com pistola, com carabina 44"

\section{ANDRÉ GARCIA} SECRETÁRIO ESTADUAL DE SEGURANCCA

mento na ponte. $\hat{E}$ bom destacar que a ponte erao alvo. Dizem que estamos protegendo um bem pri. vado, mas a ponte é um património público, sob ministraçáo privada. lovia um interesse de colhão de Missóes Especiais (BME), que estava lá na (BME), que estava lá ná ponte, em dois flancos de atuação, um atris e outro na trente. Algo que, sob o pontodevista daseguran. ça, é muito perigoso, porque teriamos um enfren. tamento com pessoas no vío central. Para evitar que isso ocorresse, impe. dimos que a população subisse a pé de Vila Velha para Vitória. o problema ocorreu quando essas pessoas subiam a ponte.

Fomos coletando informaçóese vimos o perfil de quem estava subindo. Ha. via manifestantes pacifi. cos, mas havia outros com perfil de enfrentamento. Nảo atuamos apenas com suposições, mas com in. formaçés de quem está ormaçues de quem está

Queorientaçãoosenhor dá para a populaçăo

Não posso desmobilizar o movimento, porque nĩo é proposta do poder pú. bico. Se eu tivesse condi. çōes de dizer algo é que o movimento está perdendoseu propósito. lssoestá evidente. Muitos estâo se aproveitando do movi. mento. E essas pessoas perigosas - prendemos pessoas armadas com pis. tola comearabina 44-es. 5odoseulado, dolado todadode um pai, de uma maie de fa. Quen, de uma criança. Quem garante que essa arma não vai ser utiliza. da? Ou em que momento ela vai ser utilizada? E al. go a se pensar. Acho que o movimento já perdeu a sua característica, que foi beleza da marcha dos 100 mil.

\section{"Sem ação da PM, haveria o dobro de crimes"}

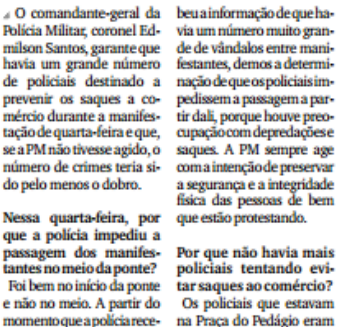

da tropa de choque, que prendenda. Pode ter certenão é destinada a policia. zadeque, sea PMnãotives mento preventivo. Mas ha. se agido, teria havido pelo via urenentivo. Mas ha. se agico, teria hasido peio via um numero de poticiais muito grande destinado para resguardar a seguran. Por que a policia nãoconça dos manifestantes e agir segue impedir a açio do hoc casos de vandalismo e saqueadoresevandalos? saques. O problema équeo As manifestaçỉes tền tranumero de criminosos com zido um número cada ve: o objetivo de vandalizar e maior de criminosos. Um saquear o comércio era dos rapazes presos ontem muitogrande.Condurimos (quarta) estava com uma 30 DPJ de Vitócia 150 pes. pistola 380; e o cutro, orm soas 0 delegado teve oue uma carabina 44. Abortar pedir reforro para que os umapessoadescas podege presos fosem vigiados, an rar mito pinico pode quantoPMs voltavamàma. podem ser baleadas. No

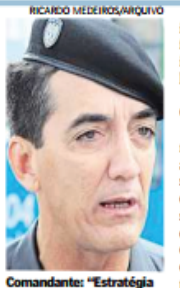

infiltrados entre os mani. festantes. A gente observa, identifica o criminoso $e$, na hora certa, aboeda.

Como a policia agiráhoje? A PM năo vai agir de ma. neira repressora, mas para assegurar a integridade $\mathrm{f}$. sica dos manifestantes e evitar crimes. A estratégia será definida de acordo com informaçós na hora do protesto. Á gente pede que os cidadasos de bem pensem duas vezes antes de ir ao protesto, pois o contingente de bandidos nas manifestacōes com o objetivo úniog de praticar crimescontrapopaticar érimescontraop

Anexo 3 - Entrevistas (A GAZETA, 28/06/2013: 10). 


\section{“Ação da PM é quase perfeita”, diz coronel \\ A Alvo de críticas, princi- palmente nas redes so-
ciais, a açăo da Polícia Mi- litar nas manifestações de protesto registradas em Vi-
toria, desde junho, é consi- toria, desde junho, é consi- da corporação, coronel Ed- \\ Segundo ele, seis casos speitos de abusos pratica. manifestaçōes, sáo alvo de apuraçáo pela Corregedona foram denunciados por pes. soas que afirmam ter sid agredidas - três delas ating: \\ Os outros dois episódios quando registrava a ação envolveram estudantes do dos policiais, na última se- Laboratónio de Estudos so- (Labic) da Ufes, quetiveram cameras retidas e parte das
imagens apagadas por mili- tares -, e a professora Keila O prazo para apuraçāo dias,e, dependendodoca- \\ inquérito policial militar. fazem uso de spray de pi- variam puniçôes previstas moral, militar até sua exclusăo da "Toda vez que houver corporação, de acordo com manifestação vamos agir o que a apuração concluir. para garantir a segurança Ocoronel diz que mili- da populaçâa. Desde a dita- tares são orientados a evi- dura, a PM mudou muito, tar confronto físico com mas não mudou a açăo do manifestantes. Usamescu- vandalos que utilizama luta dos para se proteger de pe- democráticapara destruir dradas epauladase, visan- causar tumulto", diz o co-}

CIDADES9

DADS9
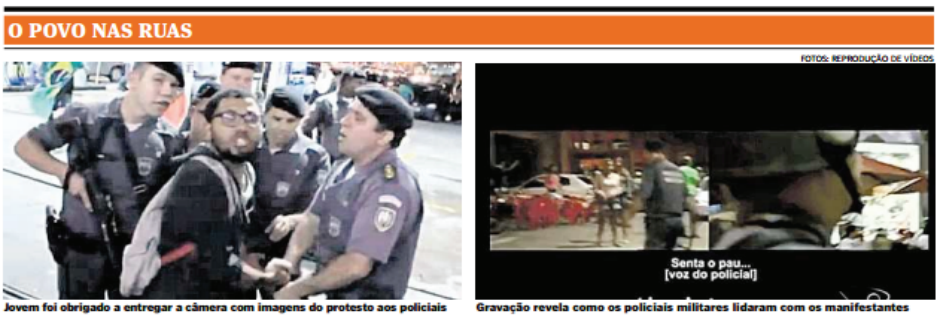

PM APREENDE CÂMERAS DE ESTUDANTES DA UFES

Jovens estavam filmando abordagem da polícia em posto de gasolina

\begin{tabular}{|c|c|}
\hline \multirow{2}{*}{ 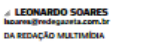 } & \multirow{2}{*}{$\begin{array}{l}\text { gasolina que fica notraje. } \\
\text { to da manifestaçăo. Os } \\
\text { manifestantes seguiam }\end{array}$} \\
\hline & \\
\hline & para a Terceira Ponte. \\
\hline & \\
\hline Fe & \\
\hline & \\
\hline & \\
\hline & \\
\hline & \\
\hline & \\
\hline & \\
\hline & \\
\hline & \\
\hline & 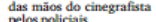 \\
\hline & \\
\hline & \\
\hline
\end{tabular}

Imagens fazem parte de estudo da universidade

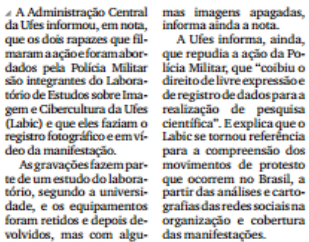

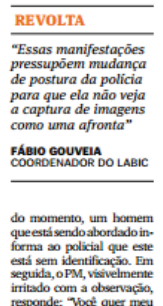

noene?". Em seguida, retira a identificacio que estava eaproxima do orosto do ma. nifestante, enquantochain

ojovem de "tabseac",
O mesno policial, identificadono video comosargento Gomes, olla para a câmerae diz" Aqui. Gomes. Tira foto de mim". E e novamente questionado por tem necessidade de fare isso, cara", diz o rapaz. mandam que os bomen abordadosvirem de costase comecam a revisti-los. E nesse momentoqueum dos policias tenta retirar a ca. OAB/ES: "Filmar não representa crime"

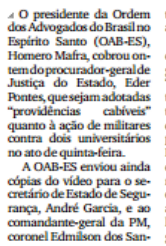

tos, e informou que vad acompanhar a apuraçäio. Homero Marra afirmou, de acordo com nota divul"o direito de manifestacti tem que ser respeitado em que "a a a so de filmar nío re. presenta nenhum crime'. Ele ainda comparou a acti da PMcom os Estados auto. nitirinas ecompletou: "O ato de apagar imagens toma idial, uma verque sóseapa. ga a que se quer esconder"

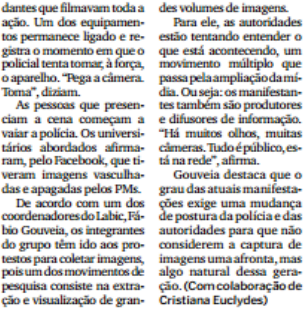

Corregedoria investigará atuação de policiais

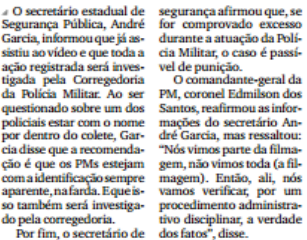

Anexo 5 - Reportagem (A GAZETA, 17/07/2013: 8). 